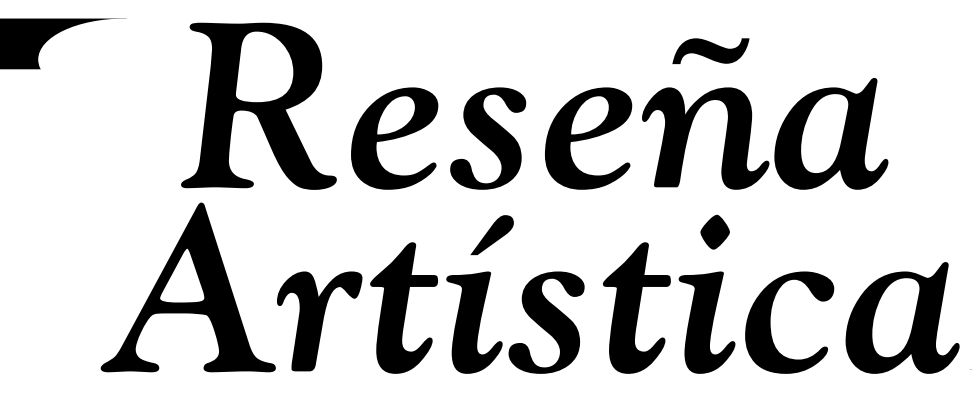




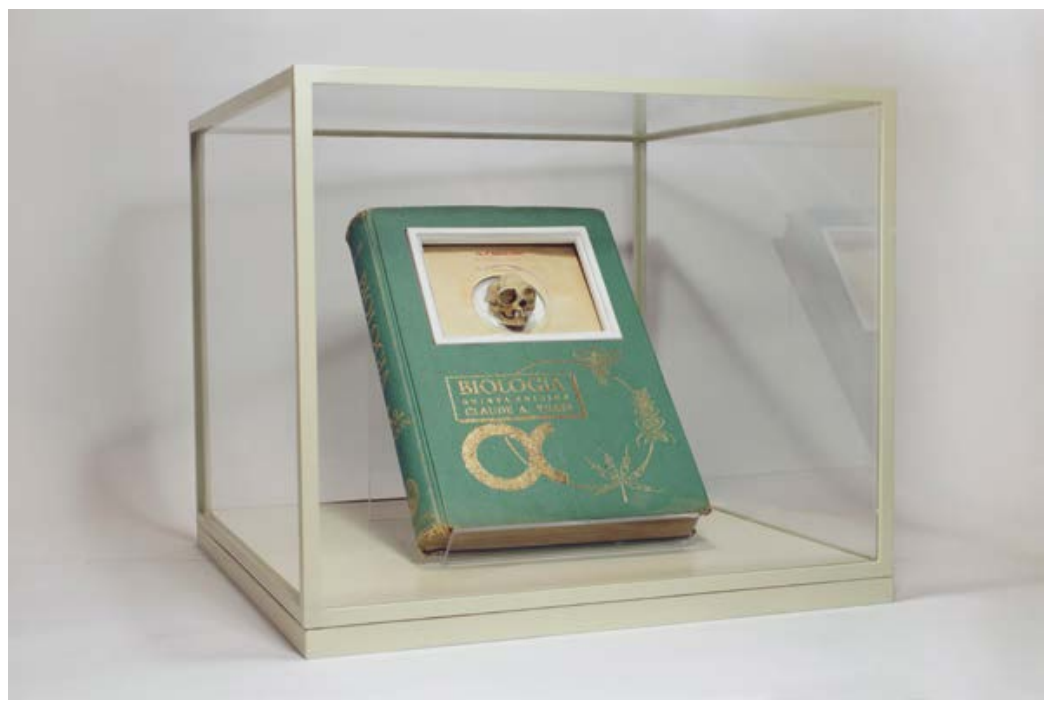

Felipe Florez. De la serie Anatomía de la Melancolía, 2012. Libro intervenido, huesos, masilla epóxica, madera y acrílico. $30 \times 20 \times 4 \mathrm{~cm}$. 


\section{Felipe Florez. Estructuras que desbordan la narrativa de su origen}

DOI: 10.17230/co-herencia.17.33.12

\section{Armando Montoya López*}

La impronta conceptual y formal de las propuestas desarrolladas por Felipe Florez radica en la confluencia entre el arte, el conocimiento teórico y la experiencia empírica: las estrategias metodológicas aplicadas en los procesos educativos de formación básica y media, en particular lo concerniente a conocimientos científicos, en algunos casos. En otros, las noticias registradas por los medios de comunicación se constituyen en la fuente primaria para indagar con rigor y encontrar hoy fragilidades tanto en el discurso como en la forma de operar.

En la actualidad, los saberes no pueden constituirse en dogmas, entre lo fluido y lo espeso hay valores que merecen atención. La realidad ya no se entiende en un solo sentido, estamos invadidos por múltiples voces que han dado pie a nuevas interpretaciones. Al menos en nuestro medio, las dinámicas de las transformaciones sociales se desenvuelven de un modo diferente. El centro se ha expandido a la periferia y, a su vez, la periferia se ha volcado al centro. La tecnología está al alcance de cualquier persona. Todos nos sentimos reporteros y algunos son reconocidos como tales.

A veces, la curiosidad por saber sobre asuntos científicos ehistóricos pone a Felipe Florez en contacto con libros y periódicos para situarlo en un contexto temporal que expande acontecimientos al margen. El punto de partida ya no interesa tanto como aquellos sucesos paralelos desplegados en la lectura. Se trata de artículos y noticias que refieren acontecimientos un tanto misteriosos, insignificantes e inconexos,

\footnotetext{
* Maestro en Artes Plásticas. Líder de la línea de investigación en artes, Corporación BANASTA Mediaciones Arte y Cultura.
} 
con un sabor tan amargo que evidencian la condición de algunos seres humanos por sobresalir sin que importen las consecuencias en relaciones basadas en el interés y el triunfalismo.

Así, va acumulando diferentes historias que se convierten en detonantes, cuando despliega los datos y cruza la información para trasladarse más allá de la hipótesis que advierte el medio de información, y propone un nuevo sentido a los objetos y a las cosas que allí reposan. La estrategia planteada se emparenta mucho con el proceder de los escritores en el sentido de comprometerse con la investigación de acontecimientos reales para luego hacer de estos una ficción en la narrativa. En esta dirección proyecta "estructuras que desbordan la narrativa que les da origen” (F. Florez, comunicación personal, julio 22-23, 2016).

A continuación, citaré algunos enunciados que detonaron las propuestas realizadas en su proceso de formación, ${ }^{1}$ que anticipan el uso y aplicación de estrategias para divagar y suscitar desconcierto en sus proyectos posteriores: "Supuestos descubrimientos científicos fueron desvirtuados confirmando un fraude" -Derivas botánicas (2009)-. Antiguos libros de texto, compendios enciclopédicos cuyos contenidos aún se toman como "portadores de una verdad" transmitida de generación en generación -Árbol del conocimiento (2009)-. Asimilación de la realidad como un desplazamiento físico y mental que valida lo que se da entre los estados intermedios -Materia oscura (2009)-. Diferentes saberes, cada uno a su manera, son argumentados a partir de un mismo problema, planteando otros puntos de vista -Cuatro métodos (2010)-. Diferentes variantes que intervienen en la construcción de la realidad a través de la percepción -Proceso de dislocación (2011)-. Reconfigurar la situación del observador que no está acostumbrado a cuestionar y rebatir la imagen en el día a día y detonar nuevas maneras de ver y explorar la realidad -El zoológico de Durero (2012-2013)-. Construcción de atmósferas dislocadas -Cacofonías (2013)-. Accidentes ocasionados por fenómenos naturales o por fallas técnicas que echan a perder proyectos científicos -Que parezca un accidente (2014)-.

1 Durante los años 2005 a 2011 realizó sus estudios en Artes Plásticas en la Universidad de Antioquia. De 2016 a 2019 hizo la Maestría en Artes Plásticas y Visuales de la Universidad Nacional de Colombia, sede Medellín. 
Una campaña de expectativa publicada por el $\mathrm{M}-19,{ }^{2}$ como antesala a la toma del Concejo de Bogotá y al robo de la espada de Bolívar, le permitió identificar las siguientes crónicas paralelas que son las que dan origen a Cuando todas las cosas reposan (2016). ${ }^{3}$ Veamos algunos fragmentos de estas historias:

Enfermos, desanimados y acaso presintiendo la muerte pasaron la última noche de su vida los dos alpinistas perdidos en la Sierra Nevada del Cocuy. Las líneas finales de un diario escrito por el inglés en una carpa que ayer se halló sepultada un metro bajo el hielo parecen resumir toda la tragedia de los dos jóvenes antes del 22 de noviembre, día en que sufrieron un accidente que les quitó la vida (El Tiempo, 1974b).

Un curioso lío se formó en una funeraria cuando la persona que figuraba como muerta en una de las salas de velación apareció viva, con sus documentos de identidad en la mano y una señora reconoció en el cadáver a uno de sus hijos (El Tiempo, 1974c).

Reconstrucción total y minuciosa de la cabeza del hombre descuartizado y enmaletado enviado a Cali en octubre del año pasado fue terminada por el laboratorio de la División de Orden Público del DAS, con base en análisis hechos por los expertos forenses para lograr la identificación de la víctima y esclarecer el misterioso y embrollado enigma policíaco (El Tiempo, 1974a).

Cerca de la osamenta fueron hallados varios objetos que pueden ayudar al esclarecimiento de lo que parece ser un crimen horrendo. A pocos metros fueron halladas unas gafas Ray Ban, un encendedor y una correa, además de dos frascos que contenían medicinas y un líquido blanco que no ha sido identificado hasta el momento (El Tiempo, 1974d).

2 Se trató de una campaña de expectativa publicada en El Tiempo, el 15 y 16 de enero de 1974, cuyo lema decía: “¿Parásitos... gusanos? Espere M-19” (El Tiempo, 1974e).

3 Exposición realizada por BANASTA. Galería, sede de Art Laboratorio, Rionegro (Antioquia), agosto 20 a septiembre 24 de 2016. Beca de creación para artistas emergentes, Área Artes visuales, Ministerio de Cultura. 


\section{Imagen 1}

Cuando Todas las Cosas Reposan

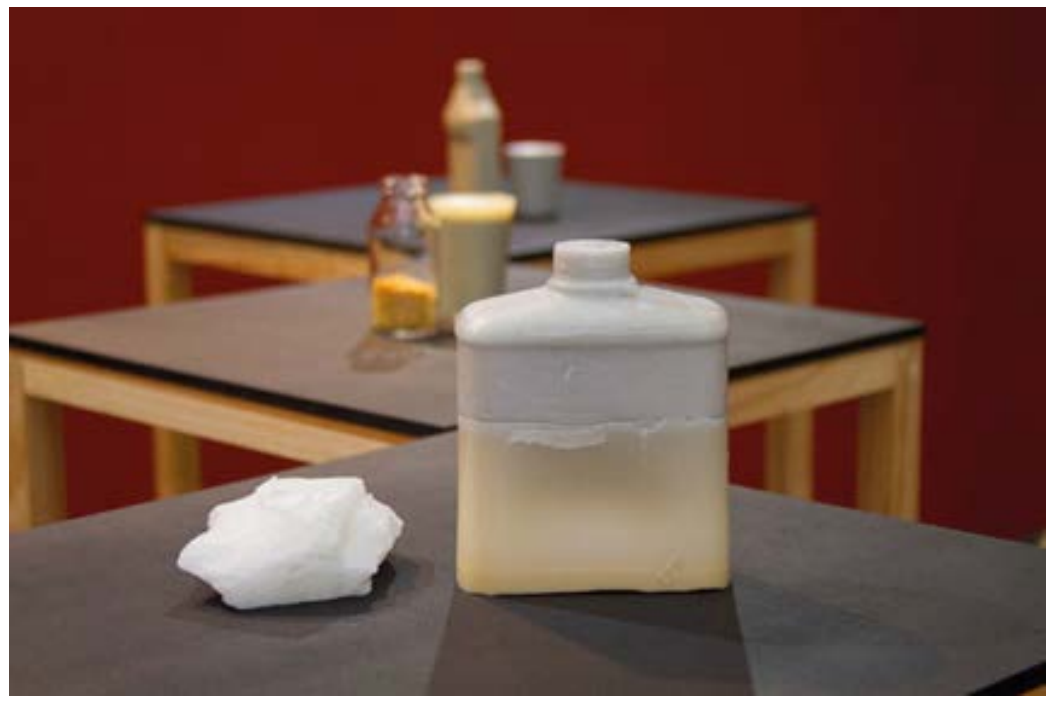

Felipe Florez. De la serie Cuando Todas las Cosas Reposan, 2016. Detalle. Ceras, carbonato de calcio y colágeno. Dimensiones variables.

Este punto de partida demandó estar en otra parte, en "algo que revive la experiencia con el arte" (F. Florez, comunicación personal, julio 22-23, 2016). En este caso, actúa como un investigador forense que indaga relatos de manera paralela. La diferencia estriba en que el forense debe resolver cada caso a partir de objetos tangibles, de pistas acumuladas, consultar la fuente directa en el sitio de los acontecimientos, confrontar la información allegada desde el punto de vista científico y sacar conclusiones. En contraposición al forense, a Felipe no le interesa comprobar nada, no busca enunciar la verdad, sino darle un sentido al universo mediante la puesta en escena -dibujos, fotograbados, objetos insólitos y una cabeza en bronce- que configuran la nueva historia, una historia ficticia o, más bien, nuevas dimensiones de la historia activada por los relatos mencionados (imagen 2). 


\section{Imagen 2}

Cuando Todas las Cosas Reposan

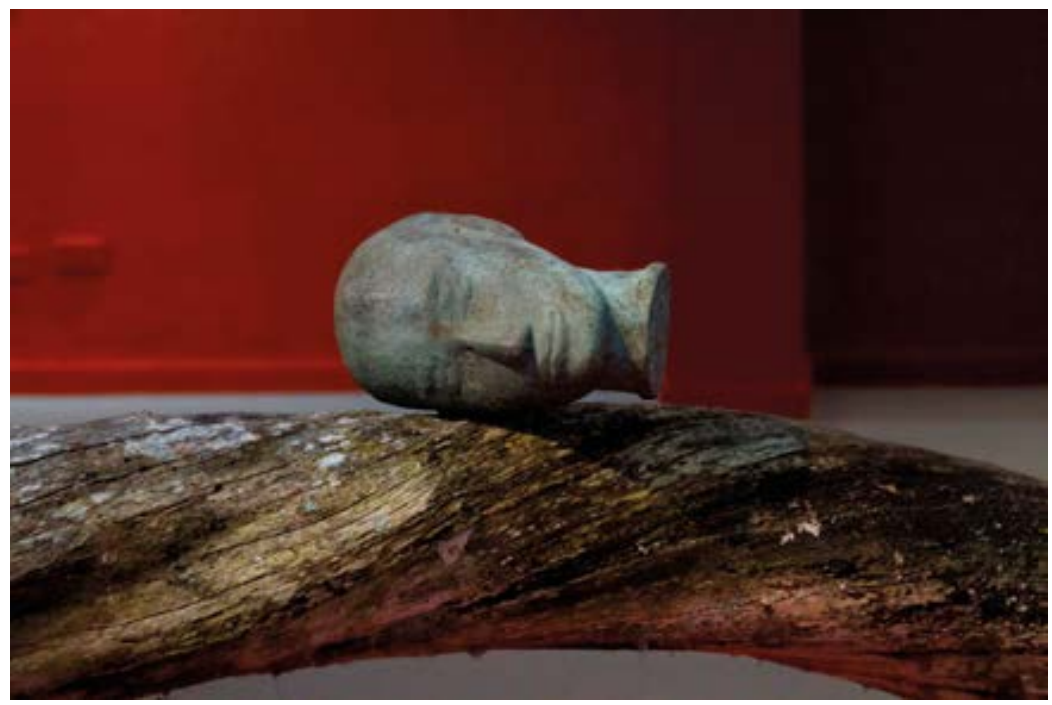

Felipe Florez. De la serie Cuando Todas las Cosas Reposan, 2016. Detalle. Vaciado en bronce y tronco de eucalipto.

El caso específico de Ecos $(2018)^{4}$ tiene su origen en las composiciones musicales del compositor norteamericano Dominick Argento, particularmente un ciclo de canciones para barítono y piano titulado The Andrée Expedition (1983), en el que Argento musicaliza textos de los diarios y las cartas de la expedición ártica de S. A. Andrée. ${ }^{5}$ Lo que inquieta a Felipe Florez es la capacidad del músico para interpretar los textos escritos que refieren la expedición $y$, en consecuencia, se pregunta por la posibilidad de desentrañar paisajes del Ártico cifrados en los sonidos de estas composiciones (imagen 3). "La propuesta consiste en el procesamiento digital del

4 Ecos (2018) es un proyecto derivado y continuado de su anterior indagación en Que parezca un accidente del año 2014, y seleccionado por BANASTA Galería para participar en la exposición Narrativas y procesos contemporáneos de las artes plásticas y visuales de Medellín, Colombia, Fundación Rozas Botrán, Ciudad de Guatemala, agosto-septiembre de 2019.

5 El 11 de julio de 1897, Solomon August Andrée, Nils Strindberg y Knut Fraenkel partieron en una expedición fallida que pretendía volar al Polo Norte en un globo aerostático. Treinta y tres años después, sus cuerpos, así como sus cartas y diarios fueron hallados y devueltos a Suecia. 
sonido presente en el ciclo de canciones, reinterpretándolas como una serie de modulaciones en una composición tridimensional virtual. El resultado es un nuevo paisaje ártico, construido en un ordenador a partir de ondas sonoras" (Florez, 2019a, s. p.).

\section{Imagen 3}

Ecos

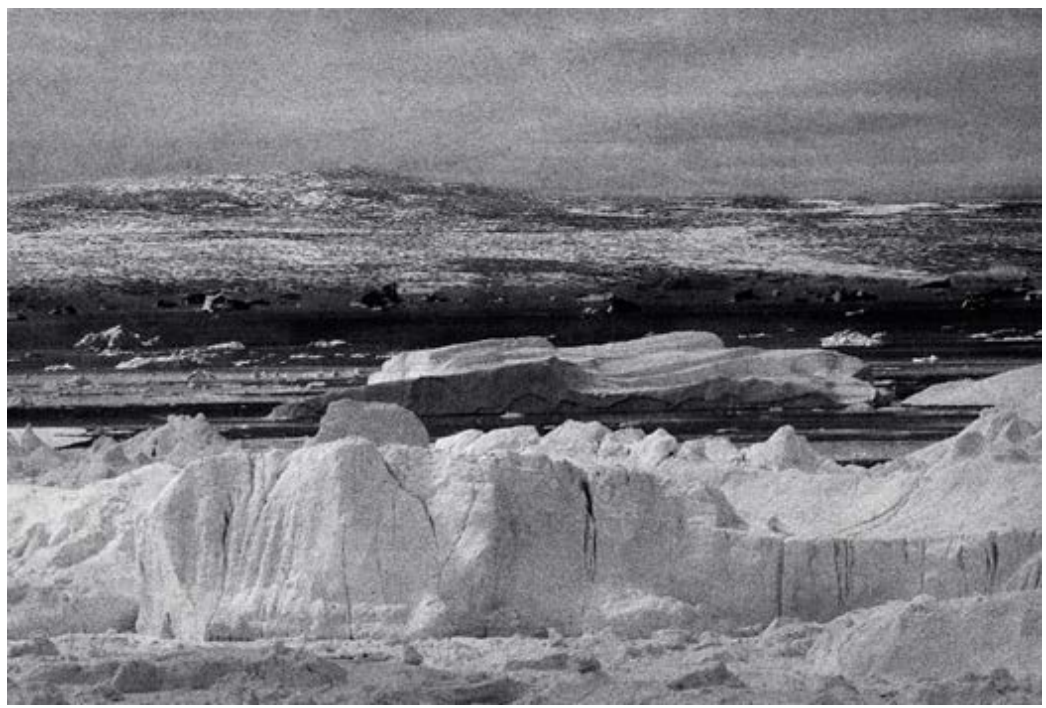

Felipe Florez. De la serie Ecos, 2014-2019. Anilinas, nitrato de plata y tinta sobre papel. 70 $\times 50 \mathrm{~cm}$.

En La Espada y La Pluma (2018-2019) ${ }^{6}$ Felipe retoma sus indagaciones sobre el M-19 y específicamente el mito que se tejió en torno al robo de la espada de Bolívar, del cual se conservan crónicas, relatos y entrevistas. Tres poetas estuvieron vinculados con la espada durante su recorrido por la clandestinidad: Nelson Osorio (1941-1997) fue el creador de la campaña de expectativa del M-19; León de Greiff (1895-1976) mantuvo la espada bajo su custodia desde 1974 hasta su muerte, en 1976; y Luis Vidales (1904-1990) quien relevó la custodia, entre 1977 y 1978. El artista escudriñó y analizó minuciosamente los

6 Exposición realizada en la Casa Museo Quinta de Bolívar, Bogotá, octubre-noviembre de 2019. Proyecto seleccionado en la convocatoria Intervenir la historia de la Casa Museo Quinta de Bolívar, el Museo de la Independencia y el Departamento de Arte de la Universidad de los Andes, 2019. 
sucesos relacionados con la espada a lo largo de la historia y propuso, además de su revisión, una lectura transversal de los acontecimientos en la edición de los libros La Espada y La Pluma, Cuaderno de Agosto y Poesía Libertaria.? Los tres libros se constituyen en la memoria de lo que significó llevar a cabo la investigación y la experimentación con el software y la máquina impresora (imagen 4).

\section{Imagen 4}

La Espada y La Pluma

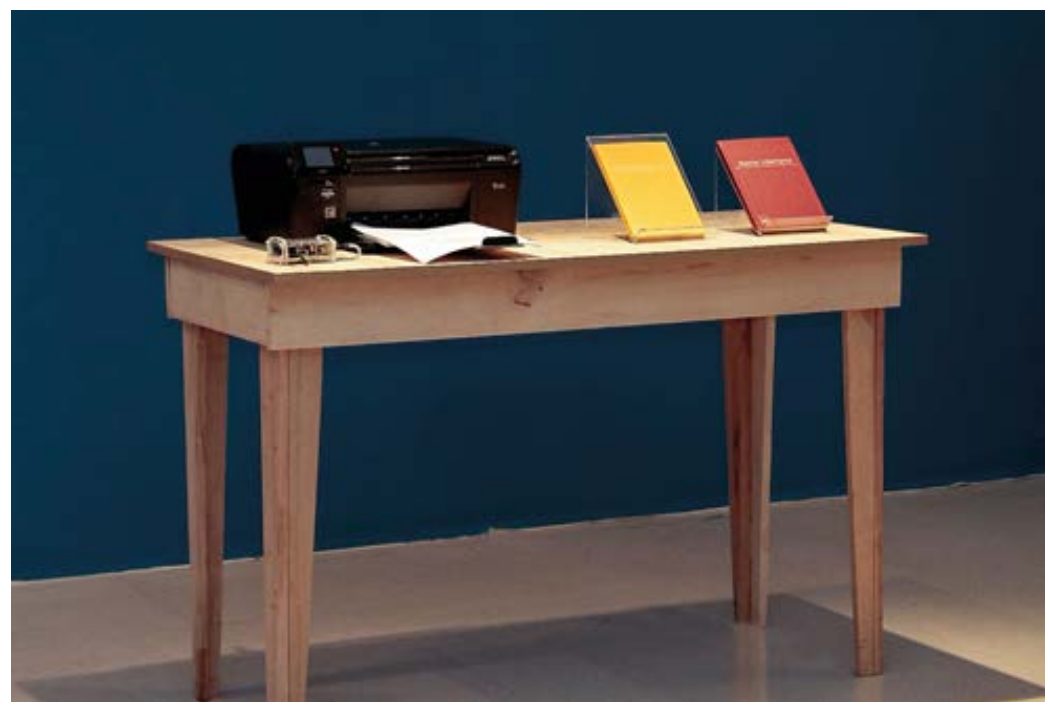

Felipe Florez. De la serie La Espada y La Pluma, 2018-2019. Impresora de inyección de tinta, tarjeta Raspberry Pi y edición encuadernada. Dimensiones variables.

Para la concreción del proyecto, Felipe rastreó la totalidad de los textos producidos por cada uno de los poetas durante el tiempo en que entraron en contacto con la espada, para luego reordenarlos por medio de un software de procesamiento de lenguajes naturales, el cual los descompone sintácticamente para producir una serie de

7 Los tres libros fueron publicados en el año 2018, en una edición de cien ejemplares de cada título. La Espada y La Pluma es una especie de novela que narra los sucesos cruzando la realidad con la ficción, narrada amenamente por un personaje ficticio que podría ser el símil de un guía de la Casa-Museo. Cuaderno de Agosto compendia ideas sueltas, registros fotográficos, artículos de prensa, referentes literarios y artísticos. Poesía Libertaria es apenas el primer volumen de un infinito número de volúmenes que podrían editarse como resultado de los sucesivos poemas aleatorios impresos mientras el dispositivo esté operando. 
nuevos poemas a partir de estructuras gramaticales dadas. A su vez, este software activa un dispositivo electrónico -ubicado dentro del cuarto de El Libertador- capaz de producir e imprimir estos poemas de forma aleatoria (Florez, 2019b, s. p.).

Los libros ya mencionados y los poemas aleatorios, que se archivaban en carpetas por día de impresión, se ubicaron en estanterías entre los demás libros que ya componen la biblioteca de la Quinta de Bolívar. La puesta en escena contempla además códigos QR estratégicamente ubicados, que al ser activados por los visitantes complementan la información -testimonios y discursos-. De esta manera, Felipe Florez, con sus intervenciones, nos invita a leer entre líneas para dar cuenta de los vacíos de un pasado histórico y, del mismo modo, a desafiar los centros de poder que instauran su versión como la oficial (imagen 5).

\section{Imagen 5}

La Espada y La Pluma

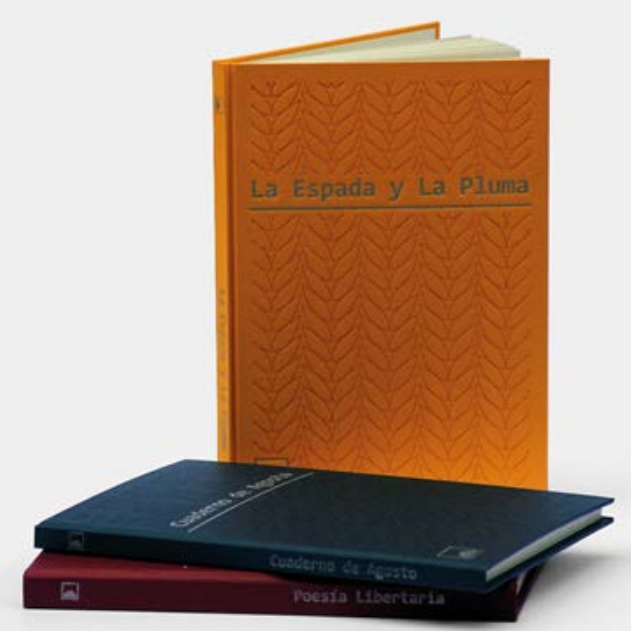

Felipe Florez. De la serie La Espada y La Pluma. Tres ejemplares de la edición de 2018 (v. nota 7 , supra), $21 \times 15 \times 1,2 \mathrm{~cm} \mathrm{c} / \mathrm{u}$.

UNO : UNO (2019) ${ }^{8}$ es una propuesta que de común acuerdo reúne dos disciplinas: las artes visuales y la literatura -artista frente

8 La propuesta, realizada por Felipe Florez y Felipe Ospina, hizo parte de la exposición Lo que te diga es mentira, Sala U, Universidad Nacional de Colombia sede Medellín, 2019. 
a escritor- en una experiencia cartográfica a escala natural -1:1-, lo que quiere decir que el tamaño físico del objeto representado en el plano coincide con la realidad. Si bien la cartografía es un mapa y un mapa es una grafía, también la grafía podría ser un texto. En torno a esta idea, el artista y el escritor elucubraron notas, dibujos, esquemas en papel, ideas itinerantes. Siempre estuvo presente el papel como soporte para previsualizar el mapa, el territorio de experimentación. Todo apuntaba a la construcción de un mapaterritorio que no privilegiara ni los textos ni las imágenes: no en vano Sebald llamaba a la escritura "la pintura de la voz" (citado por Gordo, 2015, párr. 5). Entonces se dieron a la tarea de aunar y luego destruir todos los papeles contenedores de sus ideas acumuladas durante años; licuaron, amalgamaron la pulpa y fabricaron un papel artesanal. El resultado fue un territorio de papel, un mapa con nuevas dimensiones en el que se identifican las coordenadas de los sitios de donde se extrajeron las muestras, una especie de "biopsia" que al ser observada con un Microscopio de barrido de electrones (MEB) revelaba microcosmografías insospechadas, sorprendentes y azarosas según el sector examinado, que se registraron fotográficamente. El nuevo papel-mapa-territorio develaba además sutiles huellas de la tinta de aquellas grafías que aún pervivían pese a su destrucción. Siempre es bueno saber y conocer sobre aquel lugar que marcamos en el mapa.

Felipe rastrea objetos y cosas en lo intangible de las lecturas y pone en cuestión la veracidad de lo observado y su relevancia dentro de la experiencia directa con la realidad. Identifica pues sucesos cuyos hechos se han falseado en la narración y explora especulativamente el mundo en los soportes que contienen la información, algunas veces narrada por personas ajenas o no especializadas en el tema. También, aquellos donde los procesos de recolección de datos son alterados por manipuladores expertos con ánimo de reconocimiento científico. Él se queda con los discursos aportados en los diferentes medios de información, establece conexiones entre las crónicas y los documentos, no importando sus disciplinas o saberes y disecciona, desbarata la percepción real sin preguntarse por la veracidad de lo escrito. Tampoco busca un destino, pero sí busca nuevas experiencias estéticas; en este sentido escoge y despliega sin jerarquías, de manera plana, en sentido horizontal y diluido más que vertical y concentrado. 
Su objetivo es crear estrategias y procesos que le permitan "entenderse mejor" al tomar decisiones que originan un pensamiento más eficiente cuando define nuevas percepciones poéticas y nuevas formas e imágenes que surgen de su imaginación, cuando las hace tangibles a través de procedimientos técnicos propios de la escultura, el dibujo y las nuevas tecnologías. La formalización se activa ahora, en consonancia con el sistema propio que suscitan los objetos en la narrativa y la construcción simbólica del acontecimiento, como también por la esencia misma de la composición orgánica de los materiales. En una especie de "alquimia renovada", Felipe Florez deconstruye mitos y creencias para dar forma plástica a su visión del mundo, ubicándonos en la incertidumbre, en el filo de la navaja. Cada objeto nuevo contiene el eco de un pasado atrapado en el gesto de hoy $\mathbf{C}$

\section{Referencias}

Culmina la reconstrucción del rostro del enmaletado. (1974a, enero 15). El Tiempo, 12C.

Diario de alpinistas (I): Enfermos presentían la muerte. (1974b, enero 15). El Tiempo, 1A.

Florez, F. (2018). La Espada y La Pluma. Cuaderno de Agosto. Poesía Libertaria. Nueva Compañía Bolivariana (NCB) [impresión y encuadernación: Talante, Taller de impresión, Medellín].

Florez, F. (2019a). Dossier de la Exposición Narrativas y procesos contemporáneos de las artes plásticas y visuales de Medellín, Colombia. Fundación Rozas Botrán [Ciudad de Guatemala, agosto-septiembre, 2019].

Florez, F. (2019b). Dossier de la Exposición La Espada y La Pluma. Casa Museo Quinta de Bolívar, Museo de la Independencia y Departamento de Arte de la Universidad de los Andes [Bogotá, septiembre-octubre, 2019].

Gordo, A. (2015, agosto 24). La vieja costumbre de la tinta y el papel. El Cultural. https://bit.ly/3bzSDtC

Muerto sin nombre apareció en Bogotá. (1974c, enero 15). El Tiempo, 2A.

Otro hallazgo macabro en la carretera a oriente. (1974d, enero 15). El Tiempo, 12C.

¿Parásitos... gusanos? Espere M-19. (1974e). El Tiempo, 2C. 


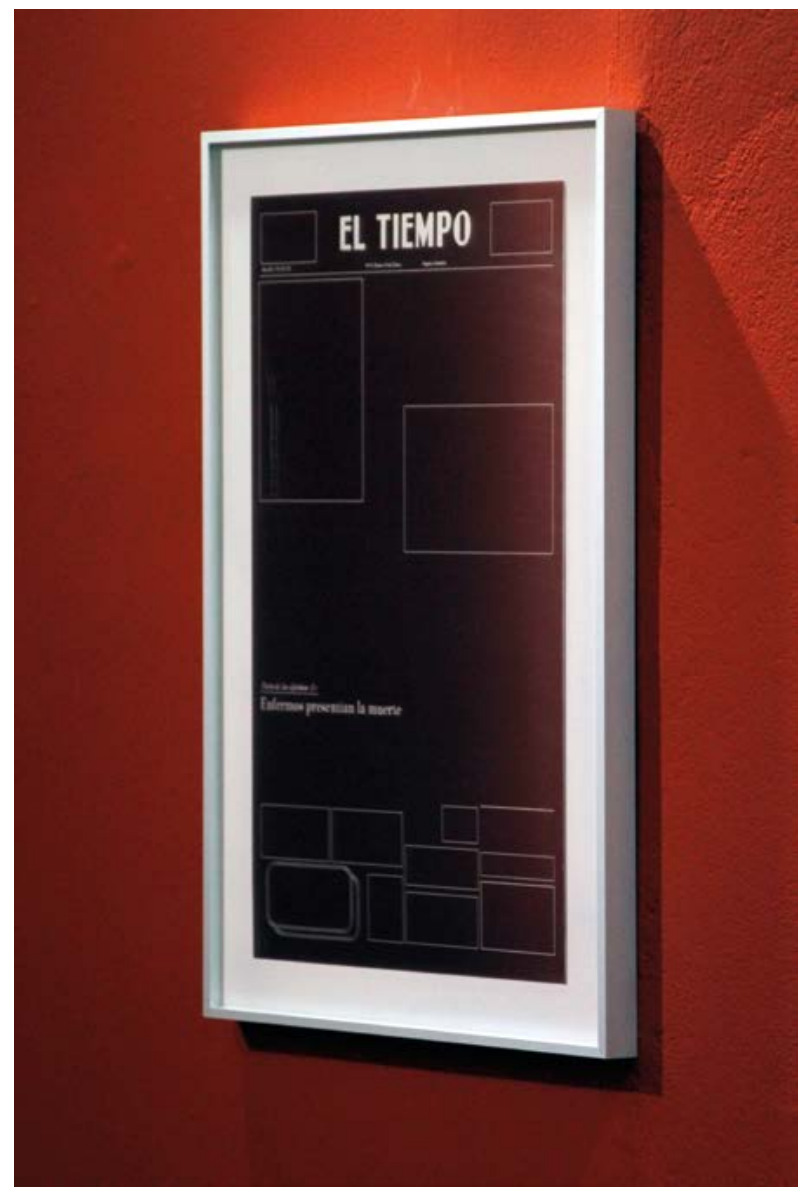

Felipe Florez. De la serie Cuando Todas las Cosas Reposan, 2016. Detalle. Grabado láser sobre acero inoxidable. $65 \times 40 \mathrm{~cm}$. 
